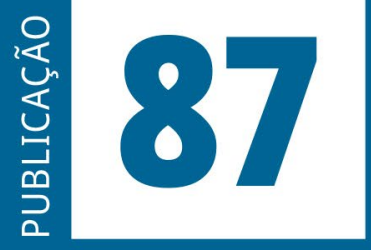

ISSN: 0101-9562

ISSN ELETRÔNICO: 2177-7055

SEQÜENCIA

Publicação do

Programa de Pós-Graduação em Direito da UFSC

VOLUME 42 - ANO 2021
Estudos jurídicos e políticos 
SEQUÊNCIA - ESTUDOS JURÍDICOS E POLÍTICOS é uma publicação temática e de periodicidade quadrimestral, editada pelo Programa de Pós-Graduação Stricto Sensu em Direito da Universidade Federal de Santa Catarina - UFSC.

SEQUÊNCIA - ESTUDOS JURÍDICOS E POLÍTICOS is a thematic publication, printed every four months, edited by the Program in law of the Federal University of Santa Catarina - UFSC.

Versão eletrônica: http://www.periodicos.ufsc.br/index.php/sequencia

A publicação é indexada nas seguintes bases de dados e diretórios/

The Publication is indexed in the following databases and directories:

Base OJS

Base PKP

CCN (Catálogo Coletivo Nacional)

Dialnet

DOAJ (Directory of Open Access Journals)

EBSCOhost

Genamics Journalseek

ICAP (Indexação Compartilhada de Artigos de Periódicos)

Latindex

LivRe!

OJS
PKP
Portal de Periódicos UFSC
Portal do SEER
ProQuest
SciELO
Sherpa/Romeo
Sumarios.org
ULRICH'S
vLex

Ficha catalográfica

Seqüência: Estudos jurídicos e políticos. Universidade Federal de Santa Catarina.

Programa de Pós-Graduação em Direito. n.1 (janeiro 1980)-.

Florianópolis: Fundação José Boiteux. 1980-.

Publicação contínua

Resumo em português e inglês

Versão impressa ISSN 0101-9562

Versão on-line ISSN 2177-7055

1. Ciência jurídica. 2. Teoria política. 3. Filosoia do direito. 4. Periódicos.

I. Universidade Federal de Santa Catarina. Programa de Pós-graduação em

Direito

CDU 34(05)

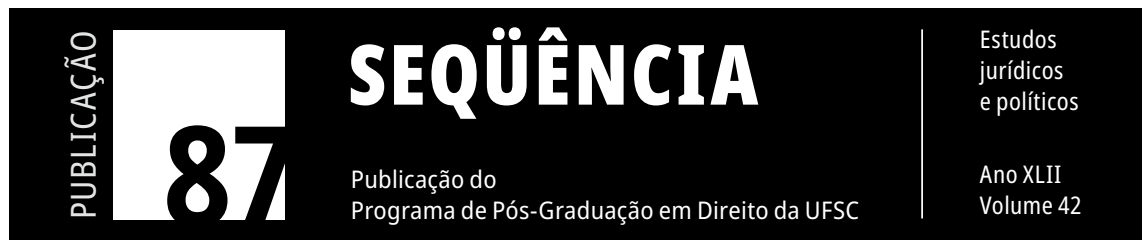




\title{
Direito à terra na América Portuguesa: petições de indígenas e doação coletiva de sesmarias na capitania do Ceará (Século XVIII)
}

\author{
Right to land in Portuguese America: indigenous petitions and \\ coletive donation of sesmarias in the captaincy Ceará (18 th $^{\text {century) }}$
}

\author{
Gustavo César Machado Cabral \\ Universidade Federal do Ceará, Fortaleza, Brasil \\ Ana Carolina Farias Almeida da Costa \\ Universidade Federal do Ceará, Fortaleza, Brasil
}

RESUMO: Este artigo pretende contribuir com o entendimento sobre como a periferia do Império Português foi ocupada durante a transição do século XVII ao XVIII. Considerando a forma como a literatura jurídica portuguesa tratou o tema das terras e do direito de petição, particularmente de "pessoas miseráveis", discute-se um caso em que indígenas da Capitania do Siará Grande requereram, em petição ao Conselho Ultramarino, a concessão de terra em cima das serras na porção ocidental desse território. Examinando documentos do Arquivo Histórico Ultramarino (AHU) e focando nos argumentos dos requerentes e na decisão da Coroa, percebe-se que alguns grupos indígenas foram considerados vassalos do Rei de Portugal e, portanto, acabaram recebendo o título referente a essas terras. Palavras-ChaVe: História do Direito - Sesmarias - Índios.

ABSTRACT: This article aims to contribute with the understanding of how the periphery of the Portuguese Empire was occupied during the late XVII and first half of the XVIII century. Taking into account how the Portuguese legal literature ruled lands and the writ of petition, particularly to "persona miserabile", we discuss a case in which indigenous people from the Captaincy of Siará Grande petitioned to the Ultramarine Council to demand the concession of lands over the mountains 
in the west side of this territory. Examining the documents of the Historical Ultramarine Archive (AHU) and focusing in the arguments of the petitioners and the decision of the Crown, we realize that some indigenous groups were faced as vassals of the Portuguese king and therefore received the title over these lands. KEYWORDS: Legal History - Lands - Indigenous people.

\section{INTRODUÇÃO}

As terras que vieram a compor a chamada capitania do Siará Grande, atualmente compreendidas majoritariamente no Estado do Ceará, foram inicialmente doadas a Antônio Cardoso de Barros. A doação, que aconteceu em 1535, acabou não acarretando a posse da área pelo seu senhor. Várias tentativas de ocupar essas terras se sucederam desde o início do século XVII, como a construção do Forte de São Tiago na barra do rio Ceará, em 1603, bem como de outras fortificações, destacando-se o Forte de Nossa Senhora da Assunção, ainda na primeira metade do século XVII. A ocupação promovida nesses núcleos não teve caráter de efetiva colonização por não estar destinada a povoar a capitania; a função das fortificações era, sobretudo, vigiar a costa e servir de apoio às embarcações viajantes.

Uma historiografia renovada afirma que "o processo de conquista da capitania do Siará Grande iniciou-se a partir da ribeira do Jaguaribe em finais do século XVII" (Nogueira, 2017, p. 31) e advoga a necessidade de estudos que evitem generalizações, pois projetar a realidade histórica de regiões consideradas centrais para toda a América Portuguesa invariavelmente conduzirá a erro. O Siará Grande é exemplo de que não se pode generalizar a realidade histórica da América Portuguesa. Além do processo de ocupação ter se iniciado por motivos diferentes, sua trajetória econômica se distinguiu da do ciclo do açúcar, em virtude do foco na pecuária e na agricultura de subsistência, o que ajuda a compreender a relevância da ocupação no interior da capitania. 
Tampouco é possível generalizar as relações jurídicas que diversas capitanias traçavam com a Coroa, notadamente no que diz respeito à terra e às sesmarias. Nesse caso, as terras eram importantes para a formação de pastos e rebanhos utilizados para a alimentação, produção de artefatos de couro ou como força motriz dos engenhos, mas, apesar da sua relevância para o cotidiano colonial, a pecuária foi pensada como atividade secundária e atrelada à economia do açúcar, constituindo-se economia de subsistência em um contexto de predominância de uma produção para exportação (Cf. Oliveira, 2009, p. 505-516).

Tendo como base esse processo de ocupação da capitania do Siará Grande e partindo de uma discussão sobre o regime jurídico das pessoas e das terras no direito português e a sua materialização na América Portuguesa, este artigo pretende examinar em especial uma doação de sesmarias na região da Ibiapaba, na fronteira ocidental da capitania. $\mathrm{O}$ caso tem particularidades que justificam uma atenção específica: trata-se de uma doação coletiva feita aos indígenas que viviam na Ibiapaba, para a qual colaboraram os jesuítas da missão na região e que envolveu uma discussão jurídica relativamente longa, estendendo-se por quase toda a primeira metade do século XVIII. Trata-se de situação que permite uma análise cuidadosa de como se construiu juridicamente a ocupação de terras nessa área da América Portuguesa, um processo complexo que envolveu vários atores e instituições.

Antes de se analisar em particular o caso dos índios da Ibiapaba, serão discutidos o regime jurídico das pessoas e das terras no direito português e como isso se manifestou na América Portuguesa, bem como a presença indígena e o papel dos jesuítas no processo de ocupação da capitania. Pensar no poder de agência dos indígenas, principalmente a partir das petições direcionadas aos oficiais e aos conselhos da Coroa no tocante às terras, é uma etapa necessária para se chegar ao ponto final do trabalho, no qual o referido processo sobre as sesmarias na serra da Ibiapaba será o centro das atenções. 


\section{REGIME JURÍDICO DAS PESSOAS E DAS TERRAS NO DIREITO PORTUGUÊS}

Neste tópico, os dois eixos iniciais deste artigo são apresentados para a discussão, com um olhar para os tratamentos jurídicos das pessoas e da terra, notadamente no que diz respeito à possibilidade de se pleitearem direitos, sejam em juízo ou diretamente ao rei.

\subsection{Pessoas e Personae}

A distinção entre pessoas e coisas, sujeitos e objetos, não teve, durante a Idade Moderna, o mesmo significado que veio a adquirir na contemporaneidade. Por mais que o direito romano clássico tenha trabalhado com uma divisão tripartite entre pessoas, coisas e ações para, com fins didáticos, tratar da imensa maioria dos temas jurídicos, como fizeram as Institutas de Justiniano, e por mais que muitos autores do direito comum tenham se valido dessa separação, é importante perceber que as ideias de pessoas e de coisas, no discurso jurídico moderno, guardam distinções.

António Manuel Hespanha chama a atenção para a amplitude do conceito de coisa, cuja natureza nesse período era fluída e dependia dos negócios jurídicos que as nomeavam, constituindo-se um fato jurídico e não um fato natural, alcançando tanto coisas que existiam apenas no mundo do direito quanto outras que careciam de suporte material, como os direitos, ou mesmo as pessoas (Hespanha, 2015, p. 308-311). Nesta situação, além do exemplo da escravidão, o autor traz os casos de utilidades integradas num patrimônio que fossem constituídas por fatos pessoais e ações humanas concretas, como o que chamou de "a coisa mosteiro", que alcançava um conglomerado de poderes sobre as múltiplas coisas e pessoas desse mosteiro (trabalhadores, criados, foreiros, súditos jurisdicionais, monges, entre outros) (Hespanha, 2015, p. 311-312). 
O conceito de persona dá conta dessa aproximação justamente porque, diferentemente da ideia de sujeito de direitos, que precisou esperar até o período do constitucionalismo para se firmar, contempla, de alguma forma, tanto coisas quanto pessoas. Seguindo um processo de reconstrução empreendido por Bartolomé Clavero, percebe-se que persona englobava tanto pessoas quanto coisas por estar associada à legitimidade processual para atuar no mundo do direito em nome de interesses próprios, alheios (por mandato) ou coletivos ou comuns (CAlvero, 2016, p. 41). Ter persona não convertia algo em pessoa e nem em indivíduo, categoria que apenas com o liberalismo ganhou contornos definitivos. No entanto, isso significava a possibilidade de fazer pleitos ao rei ou em juízo, de modo que determinados grupos, mesmo não possuindo um status que lhes garantisse plenos direitos, poderiam pleitear certas questões por serem dotados de alguns direitos. Coletividades ou coisas atuando em juízo no Portugal moderno não eram fatos propriamente excepcionais, e Manuel Álvares Pegas, na segunda metade do século XVII, trouxe nas suas Resolutiones Forenses practicabiles muitos desses casos, envolvendo desde conventos a câmaras municipais (CABraL, 2019, p. 301-326).

A noção de privilégio aparece como essencial nesse contexto por possibilitar que pessoas singulares ou em grupos recebessem um tratamento diferente em relação a um regime jurídico geral. Estudos como os de Heinz Mohnhaupt (2000, p. 275-294; 2000, p. 371-400; 2018, p. 821-828) demonstraram a vasta presença dos privilégios na Europa Moderna, os quais atingiam diversos grupos sociais, desde alguns segmentos da alta nobreza que recebiam, juntamente com a jurisdição, o privilégio de que as suas decisões não seriam passíveis de recursos (privilegio de non appellando) até pessoas em uma posição de pobreza. Para esta situação, o caso do privilégio de ignorância é exemplar, conforme tratou, tanto para o direito (natural, civil e eclesiástico) quanto para os sacramentos e o direito divino, Giovanni Crisostomo Filippini (1688).

A categoria de persona miserabilis está diretamente associada a um conjunto de privilégios, notadamente de natureza procedimental 
e relativos ao pleito de direitos em juízo, reconhecidos a pessoas de camadas sociais mais baixas ou que merecessem alguma forma de piedade pela sua condição. Os rústicos, dos quais tratou Hespanha (2017, p. 199-278), são exemplos de grupos de pessoas que cujas pobreza e ignorância justificavam uma disciplina jurídica específica. Havia, no entanto, um elenco considerável de pessoas que acabavam recebendo um tratamento processual mais benéfico, como os escravos, as mulheres, os pobres, os órfãos e as viúvas.

$\mathrm{Na}$ América Colonial, a condição de miserabilis foi importante ao se lidar com a pobreza (Cf. Franco; Patuzzi, 2019, p. 2-27), mas o seu uso na disciplina das populações indígenas foi notável e, como demonstrou estudo seminal de Paulino Castañeda Delgado (1971), até mesmo fundamental para entender a sua condição jurídica. Essa percepção foi compartilhada por textos como o de Caroline Cunhill (2011) e, principalmente, de Thomas Duve, que examinou os debates jurídicos e morais nos quais os indígenas foram retratados como miseráveis e que, por isso, mereceriam um tratamento privilegiado perante tribunais eclesiásticos e seculares (2008, p. 166-204). Se, por um lado, isso significou menos formalidades e mais flexibilidade no tratamento jurídico (Duve, 2017, p. 57-58), essa condição partiu de uma situação de inferioridade: como demonstrou Pedro Cardim, os miseráveis eram pessoas incapazes de se autogovernarem e que mereciam uma tutela especial, semelhante aos menores, inclusive para o gozo de certos direitos (2019, p. 33-35).

Outros estudos sobre questões processuais envolvendo miserabiles na América Hispânica enfatizam o seu poder de agência e a sua atuação pleiteando, diretamente ou sob tutela, os seus direitos, como um artigo de Tamar Herzog sobre os seus direitos sobre terras (2013, p. 303-321) ou o livro de Michelle McKinley (2016) sobre a atuação em juízo de escravos em Lima no século XVII. O que une trabalhos como os das duas autoras é a perspectiva, também encontrada no já mencionado texto de Pedro Cardim para o caso português, de que houve uma conversão de direitos indígenas em direitos espanhóis a 
partir da sua subordinação a determinadas condições (no caso, o uso da terra) que poderiam ser reduzidas a fórmulas previstas no direito comum e no direito próprio espanhol (HERZOG, 2013, p. 320). A categoria de pessoas miseráveis viabilizava, portanto, o exercício desse regime jurídico e o gozo dos direitos que lhes cabiam na sua condição.

\subsection{Direitos sobre as terras}

Como acontecia regularmente no direito comum (Cf. CABRAL, 2019), o regime jurídico das terras no Império Português encontrava a sua base tanto na legislação régia quanto na literatura jurídica. $O$ pressuposto elementar da discussão é que as terras em todo o império pertenciam à Coroa, compondo a importante categoria dos bens da coroa $^{1}$. Desta forma, a Coroa tinha um papel central na concessão, manutenção e cessação de direitos sobre as terras, por ela passando as decisões eventualmente tomadas sobre essa questão, de modo que os termos em que aconteciam as discussões eram primordialmente relacionados ao exercício de determinados direitos.

Dentre eles, a posse e o domínio aparecem como muito relevantes inclusive para entender as outras relações jurídicas que poderiam se concretizar. No direito comum, a posse se relacionava a uma coisa estar em poder de alguém, podendo ser natural, quando a posse se traduzia em atos materiais de uso, ou civil, quando houvesse uma disposição puramente interna de possuir a coisa para si mesmo ou em nome próprio; ambas poderiam coexistir (Hespanha, 2015, p. 352-353). Por sua vez, o domínio alcançava, segundo autores como Domingo de Soto, a permissão de dar a destinação às coisas seguindo a nossa própria utilidade (1582, p. 99v, Lib. 4, q. 1, art. 1). Quem tinha o domínio poderia usar e dispor de forma perfeita de uma coisa, com os limites impostos pelo direito ou por convenção (Hespanha, 2015, p. 360).

Sobre os bens da coroa, cf. PORTUGAL, 1699; 
Muitos dos direitos relacionados à terra conviviam com a posse e o domínio, compondo um mosaico de direitos que recaíam em um mesmo espaço. Talvez o mais importante desses direitos tenha sido a enfiteuse, na qual o enfiteuta tinha a posse natural da coisa e dela poderia gozar por ser essa posse útil, ao passo que o senhor tinha tão somente uma posse civil que não correspondia a poderes para o uso imediato. A relevância da enfiteuse em Portugal nesse período era tamanha que Francisco Caldas Pereira, autor quinhentista de um dos mais importantes manuais sobre o tema no direito comum, chegou a se perguntar se o reino de Portugal não seria uma única e universal enfiteuse $^{2}$; esse pensamento se mostra coerente com o fato de que, ao final, a Coroa seria o grande senhorio de todas as terras do império ${ }^{3}$.

De alguma forma, portanto, a enfiteuse constituía um desses limites, mas outros decorriam de convenção ou da legislação régia e acabavam limitando o exercício do direito de propriedade. Hespanha aponta, por exemplo, as restrições à propriedade urbana em Portugal em decorrência do uso de prédios para prostituição (2015, p. 376-377). Mesmo os morgados acabavam constituindo um limite à disposição sobre o bem, uma vez que deles decorria uma cláusula de indivisibilidade e de conservação baseada numa sucessão determinada pela primogenitura (Molina, 1588, p. 1-7, Lib. 1, Cap. 1). Mas, possivelmente, foi nas sesmarias que mais se sentiam os poderes de limitação ao uso e à propriedade, como se verá a seguir.

\section{REGIME JURÍDICO DAS SESMARIAS NA TEORIA E NA PRÁTICA}

Diferentemente de outros institutos com fortes raízes no direito comum, a exemplo dos já comentados domínio, posse, enfiteuse e

2 “(...) quid est regnum hoc, nisi vna, \& vniuersalis emphyteusis?”. PEREIRA, 1585, q. 11, n. 21, p. 87.

3 Ainda sobre a enfiteuse, cf. COSTA, 1957. 
morgado, nas sesmarias o papel criativo da legislação régia foi bem relevante. O marco normativo foi a Lei de Sesmarias, de 1375, posteriormente incorporada às sucessivas Ordenações do Reino até a edição utilizada por este trabalho, publicadas em $1603^{4}$. De uma forma geral, as sesmarias eram concessões de terras vagas e não cultivadas, as quais eram entregues aos particulares a fim de que nelas acontecesse o cultivo. Ele estava no centro da preocupação da Lei de Sesmarias justamente porque a sua finalidade foi resolver problemas de abastecimento de gêneros alimentícios em um contexto da crise atravessada por Portugal na segunda metade do século XIV.

As terras que poderiam ser concedidas em sesmarias se situavam tanto entre os bens régios quanto entre as áreas de outros senhorios, os quais, por sua vez, haviam recebido da Coroa direitos - inclusive jurisdicionais - sobre determinadas terras ${ }^{5}$, de modo que poderiam, se houvesse expressa previsão no seu instrumento de constituição, doar parte dessas áreas a terceiros para que eles a cultivassem. Como a doação pelos senhorios era excepcional e dependia de expressa autorização régia, uma vez que os senhorios eram constituídos pelo rei, a Coroa tinha um papel central nesse processo de distribuição das terras a fim de que houvesse o cultivo (Hespanha, 2015, p. 346-347).

Do ponto de vista normativo, sesmarias e senhorios não se confundiam, o que, de alguma forma, também se observou na doutrina jurídica do período, como o já mencionado livro de Domingos Antunes Portugal sobre as doações régias. A prática, no entanto, ofereceu maiores entrelaçamentos, em especial na América Portuguesa, onde o regime sesmarial apresentou importantes diferenças em comparação com o regime geral português. Desde os primeiros momentos da sua adoção, quando o argumento da titularidade das áreas recém-conquistadas ainda residia no fato de que elas pertenciam à Ordem de Cristo,

4 O regime jurídico geral das sesmarias pode ser encontrado no Livro 4, Título 43, das Ordenações do Reino.

5 Sobre o regime jurídico dos senhorios, cf. HESPANHA, 1994, p. 388-417. 
da qual o rei de Portugal era o grão-mestre ${ }^{6}$, percebeu-se que a distribuição de sesmarias coube muito mais frequentemente aos donatários das capitanias hereditárias, as quais, segundo o regime jurídico das doações régias, eram senhorios (CABRAL, 2015, p. 65-86). De fato, as cartas de doação das primeiras capitanias hereditárias traziam, entre os poderes doados pelos reis aos donatários, a distribuição de sesmarias ${ }^{7}$.

O progressivo insucesso do regime, ao qual se seguiu uma presença mais forte da Coroa, fez com que ela exercesse o protagonismo na distribuição de sesmarias, notadamente ao longo do século do XVII. O baixo controle sobre a concessão de sesmarias durante os primeiros tempos da ocupação da América fez com que algumas delas tivessem áreas vastíssimas, como as concedidas a Garcia d'Ávila e aos seus herdeiros desde meados do século XVI e que, depois de constituído o chamado morgado da Casa da Torre, se transformaram em um latifúndio de mais de duzentas léguas de extensão (BANDEIRA, 2000; Alveal; Barbosa, 2015, p. 78-100). Casos como este e o da família Guedes de Brito, que formalmente eram sesmeiros, acabavam se convertendo, na prática, em verdadeiros senhorios sem que tenha havido autorização régia (AlveAL, 2016, p. 41-64).

Isso acabou provocando, da parte da Coroa, uma atuação legislativa no sentido de controlar as doações de sesmarias. A Ordem Régia de 27/12/1697 determinou um tamanho padrão para as sesmarias (3 léguas de comprimento por 1 légua de largura nas áreas de agricultura), ao passo que a Provisão de 20/01/1699 instituiu a cobrança de foro proporcionalmente ao tamanho das sesmarias, aqui numa clara diferença do regime tributário aplicado às sesmarias localizadas no Reino. Recente historiografia sobre esse processo aponta no sentido de uma tentativa de controle das sesmarias pela Coroa (Alveal, 2015, p. 247-263).

Sobre o Mestrado da Ordem de Cristo, os poderes do rei e a titularidade das terras de além-mar, cf. NORONHA, 2008.

7 Para as cartas de doação, cf. CHORÃO, 1999. 
Estudos dedicados ao regime jurídico das sesmarias no Brasil costumam pensá-las principalmente a partir do contexto açucareiro, que, durante muitas décadas, foi a principal atividade econômica na América Portuguesa. É o caso do importante estudo de Laura Beck Varela, cujas características apontadas para as sesmarias implicitamente rementem a essas áreas (2005, p. 75-107). Nos sertões, contudo, a situação era diferente, tendo em vista que o uso do espaço para a principal atividade econômica desenvolvida nessa zona, a pecuária, seguia outro caminho, especialmente porque eram necessárias áreas mais amplas para a criação de gado. Nesse sentido, o caso da capitania do Siará Grande é exemplar. Assim como em outras partes do Brasil, o sesmeiro era figura socialmente relevante, e a posse das terras, além de fonte de poder econômico (tanto pelas rendas da própria produção quanto pelo arrendamento de terras a outras pessoas), era também fonte de poder político, já que essa elite sesmarial acabava por regular o acesso à terra (Nogueira, 2017, p. 42).

As sesmarias concedidas na ribeira do Jaguaribe, único rio perene em toda a capitania e, portanto, não afetado pelas secas, se caracterizaram (Nogueira, 2017, p. 35-40) pela concentração fundiária e por concessões de mais de uma sesmaria a poucos indivíduos, mas, ao mesmo tempo, houve casos de pedidos coletivos, ou seja, mais de um indivíduo solicitando terras em um mesmo requerimento ${ }^{8}$, especialmente na transição do século XVII para o XVIII. Destinadas primordialmente à pecuária de extensão, grande parte dessas terras foram agraciadas a pessoas com patentes militares, o que revela a aplicação da lógica da gratidão e da economia da graça, elemento típico do Antigo Regime (Hespanha, 2017, p. 121-162). Além disso,

\footnotetext{
Foi o caso de uma sesmaria de 50 léguas quadradas concedida em 05/01/1685 a dez sesmeiros (cada um receberia cinco léguas de comprimento por uma de largura), localizada às margens do rio Banabuiú, próximo ao Jaguaribe. Um dos sesmeiros, Teodosio Grassiman, foi capitão de cavalos, comissário geral da cavalaria e tenente e recebeu nada menos do que seis sesmarias entre 1681 e 1707. Disponível em: <http:// www.silb.cchla.ufrn.br/sesmaria/CE\%201445>. Acesso em: 05/12/2019.
} 
a conquista das terras não ocupadas era considerada uma forma de prestação de um serviço ao rei, e, com base nisso, o vassalo poderia fundamentar o seu pedido de sesmaria. Justificativas comuns para o pedido de sesmarias na região do Jaguaribe foram a necessidade de se aumentar a arrecadação para a Fazenda Real e a guerra contra os indígenas, o que se configurava um serviço prestado ao rei que seria recompensado com a concessão da sesmaria.

Em estudos sobre a eficácia da Ordem Régia de 1697 nas capitanias do norte (Pernambuco, Itamaracá, Paraíba, Rio Grande e Siará Grande), Carmen Alveal (2015, p. 78-100) constatou que, à primeira vista, o Siará Grande foi a capitania em que mais se desatenderam as determinações sobre o tamanho das sesmarias; no entanto, como os atos régios contemplavam vários pedidos, a divisão da área concedida pelo número de sesmeiros costumava resultar no tamanho ideal de 3 léguas quadradas. Apesar de a média das áreas ter sofrido notável diminuição, não foram raros os casos em que se concederam sesmarias fora das regras de tamanho, como uma concessão de 40 léguas quadradas na Paraíba e outro com 21 em Pernambuco. Desta forma, apesar de essas normas possivelmente terem sido obedecidas na maioria dos casos, houve situações de não cumprimento.

\section{JESUÍTAS, INDÍGENAS E A OCUPAÇÃO DO LESTE DA CAPITANIA DO SIARÁ GRANDE}

A ocupação da capitania do Siará Grande se iniciou efetivamente no século XVII, período do qual datam, inclusive, várias concessões de sesmarias, mas se intensificou no seguinte ${ }^{9}$, quando

\footnotetext{
Em uma pesquisa na base de dados da Plataforma SILB, encontraram-se 48 sesmarias quando, no campo "Data concessão", indicou-se o período entre 01/01/1601 e 31/12/1700; quando o período passou a ser entre 01/01/1701 e 31/12/1800, encontraramse 1235 sesmarias. Disponível em: <http://www.silb.cchla.ufrn.br/busca>. Acesso em: 05/12/2019.
} 
foram criadas as primeiras vilas. Entre as 18 vilas erigidas entre 1700 e 1820, muitas foram criadas a partir de aldeamentos indígenas, como as vilas de Soure (atual município de Caucaia), Arronches (atual bairro da Parangaba, em Fortaleza), Messejana (atualmente um bairro em Fortaleza), Baturité e Viçosa. Isso fez com que os documentos coetâneos as denominassem "vilas de índios", em contraposição às chamadas "vilas de brancos"10.

Em 15 de agosto de 1700 foi fundada a Aldeia de Nossa Senhora da Assunção nas Serras de Ibiapaba, com diversos grupos indígenas (tapuias, anacés, aconguaçus, reriiús e tabajaras), entre os quais os tupinambás do interior e os tabajara da Bahia que, em um processo de migração ao longo dos tempos, resultou em formas de relações interétnicas entre não índios e entre outros grupos nativos. A posição geográfica em que se situava o aldeamento era privilegiada e estratégica: além de servir como porta de entrada para as missões colonizadoras no Maranhão, também funcionou como fronteira com o Piauí e como defesa aos fazendeiros do interior. Ou seja, para a historiografia, a Ibiapaba é uma categoria analítica "compreendida como uma região colonial, espaço social de interação história, com participação de diversos agentes coloniais" (MAIA, 2010, p. 20).

A partir de 1716, a Coroa acabou por assumir encargos de experiências urbanas na capitania, num esforço contínuo de impor ordem "onde o caos havia predominado" e que, "até os anos 1730, o poder administrativo português no Ceará esteve concentrado nos centros urbanos geminados de Aquiraz e Fortaleza" (Delson, 1997, p. 20-23). Nesse primeiro momento, a região da Ibiapaba não esteve no foco dos interesses da Coroa no tocante ao processo de urbanização do interior - pelo menos não nos moldes estabelecidos para as vilas de Aquiraz, Fortaleza, Icó e, por fim, em 1740, Aracati.

10 Para um panorama da ocupação e da estruturação das vilas na capitania, cf. JUCÁ NETO, 2012, p. 133-163. 
Durante o século XVII e boa parte do XVIII, vários conflitos (Cf. MeneZes, 2017, p. 161-187) ${ }^{11}$ ocorreram não só no litoral, mas também nos sertões da capitania do Siará Grande. Entre os envolvidos, havia grupos indígenas rivais, índios e brancos e mesmo entre brancos, nesse caso comumente para manter o prestígio, o poder e o domínio sobre a terra e/ou ofícios. Essa acirrada disputa e os abusos estimularam o monarca a institucionalizar a administração régia nessa capitania, reorganizando-a administrativamente (CArvalho, 2017, p. 190). Exemplo disso foi a criação da ouvidoria e da provedoria da capitania, em 1723.

Paralelamente ao clima de tensão observado em muitas áreas da capitania, observaram-se elementos diferentes em zonas como a Ibiapaba, que não fazia parte do circuito econômico do gado. Nela, a forte presença jesuíta e o aldeamento de indígenas sob influência inaciana foram marcantes, não sendo exagerado afirmar que a história da Ibiapaba se confunde com a história da presença jesuíta até a primeira metade do século XVIII. Desde o início do século XVII, os jesuítas tentaram instalar uma missão na região, o que foi frustrado ainda na primeira década do século com a morte do missionário Francisco Pinto e a escapatória do outro missionário, Luiz Figueira (Leite, 1943, p. 3-15). Em meados do século, a missão foi fundada por jesuítas oriundos do Maranhão, entre eles o padre António Vieira (Aguiar, 2011, p. 507-546), mas a instalação definitiva aconteceu a partir de 1691, sob a liderança dos padres Ascenso Gago e Manuel Pedroso, que fundaram a Aldeia de Nossa Senhora da Assunção

11 Reinaldo Forte Carvalho explica bem a situação do interior da capitania do Ceará, afirmando que a Vila do Icó, criada em 1736, teve o objetivo de "fortalecer as alianças com os moradores locais com o intuito de coibir abusos e inquietações que ocorriam na região. Nesse período, o Governador de Pernambuco Duarte Sodré Pereira Tibão pedia a elevação de Icó, justificando ao Monarca a necessidade de 'aquietação dos Povos pela distância de oitenta léguas que fica da Vila do Aquiraz de que é termo'. A justificativa do Governador coaduna bastante com o contexto de conflito e tensão que envolvia administradores locais, ouvidores, moradores e povos indígenas no processo de ocupação das terras na região da ribeira do Jaguaribe ao longo da primeira metade do século XVIII”. CARVALHO, 2017, p. 201; 
(Leite, 1943, p. 37-56), a qual, com a expulsão dos jesuítas da América Portuguesa e a extinção da missão, se converteu na Vila Viçosa Real (cf. Maia, 2010, p. 223-267). A missão teve importância fundamental nos conflitos entre indígenas que aconteceram na transição do século XVII para o XVIII e sobre ela recaíram disputas não apenas de terras, conforme se abordará adiante, mas também de jurisdição ${ }^{12}$.

Os jesuítas geriam os aldeamentos indígenas, produzindo itens fundamentais para a economia colonial. Na Ibiapaba, os negócios se concentravam na criação de gado, iniciados a partir da concessão de duas datas de sesmarias ao padre Ascenso Gago, cada uma com duas léguas $^{13}$ e que se desenvolveram a ponto de os jesuítas possuírem, quando da sua expulsão, quatro fazendas na região ${ }^{14}$. No entanto, as questões moral e religiosa, materializadas no fenômeno da conversão ao cristianismo e da manutenção na fé cristã, eram centrais nas missões desde o início da presença jesuíta na América Portuguesa, em $1549^{15}$. Mesmo gerando reações contrárias de colonos e sesmeiro, a posição dos jesuítas contra a escravidão acabou influenciando a Coroa, que instituiu sucessivas leis proibindo a escravidão indígena desde a segunda metade do século XVI. Os índios aldeados não eram considerados escravos, de modo que poderiam servir como força de trabalho nas missões.

No mais completo estudo sobre o processo de ocupação da Ibiapaba, olhando particularmente para as relações entre indígenas e

12 No mesmo período em que se disputou a posse das terras da Ibiapaba pelos indígenas, o Conselho Ultramarino foi consultado sobre levar essa área à jurisdição da capitania do Piauhy e não mais no Siará Grande; o resultado foi a manutenção. Cf. AHU - Ceará, Papéis Avulsos, Caixa 6, Doc. 66.

13 Essas duas datas de sesmarias foram concedidas em 1706 e 1708 e estão disponíveis na Plataforma SILB. Disponíveis em: <http://www.silb.cchla.ufrn.br/sesmaria/ CE\%200180> e <http://www.silb.cchla.ufrn.br/sesmaria/CE\%200344>. Acesso em: 05/12/2019.

14 Para um panorama das atividades econômicas na missão da Ibiapaba, cf. MAIA, 2010, p. 180-191;

15 A literatura sobre a catequese e sobre as suas implicações jurídicas é bastante vasta. Entre muitos outros, cf. CABRAL, 2019, p. 275-297. 
jesuítas, Lígio Melo defende uma visão de que os indígenas possuíam uma autonomia relativa, ainda que vivessem dentro de uma estrutura social de dominação. Essa visão é compatível com importantes trabalhos relativamente recentes que reconhecem um poder de agência dos indígenas na América Portuguesa, o qual acabou sendo decisivo para algumas questões (Cf. GArCia, 2019). Para fins institucionais, os indígenas aldeados eram considerados vassalos do rei e participaram, de alguma forma, da consolidação das estruturas sociais locais; a eles eram garantidas a proteção real e a possibilidade de serem agraciados com patentes e até honras militares, decorrentes do encargo de lutarem em guerras.

Cientes dessas possibilidades e das consequências de um regime de proteção que foi enfatizado, inclusive, pelo Regimento das Missões de 1686, os indígenas se apropriaram da ordem jurídica régia para obterem benefícios diretos. O caso que será analisado a seguir é uma manifestação dessa dinâmica, segundo a qual as concessões de terras, requeridas pelos índios, decorriam da vassalagem ao rei, e as terras, solicitadas para usufruto individual ou coletivo, tinham a finalidade de diminuírem os efeitos do avanço pastoril (MAia, 2010, p. 45). Portanto, a garantia da terra aos índios passava por um processo de mediação pela ordem jurídica portuguesa.

\section{ESTUDO DE CASO: DOAÇÃO COLETIVA AOS ÍNDIOS DA IBIAPABA}

O caso que será discutido diz respeito a pedidos que, em última análise, visavam garantir aos indígenas da missão da Ibiapaba o domínio sobre as terras da parte de cima da serra. Tratou-se de um processo longo que se estendeu, em várias etapas, pela primeira metade do século XVIII. Esta discussão vai ser conduzida pelo procedimento instaurado pela carta escrita pelo ouvidor régio do Ceará, Alexandre de Proença Lemos, a D. José I em 30/01/1756, com a finalidade de pedir ao rei que ordenasse o cumprimento da sua determinação de doar sesmaria aos índios da Ibiapaba. A carta-petição inicia um procedimento oficial com a Coroa por meio 
do Conselho Ultramarino, que, depois da Restauração (1640), passou a ser responsável pela comunicação com as demais áreas do Império ${ }^{16}$.

Lemos (1709-?), que foi nomeado ouvidor da capitania do Siará Grande por carta de 05/05/1747 e cuja nomeação para o próximo posto fora dessa área data apenas de $02 / 10 / 1764^{17}$, inicia a sua narrativa informando que, no dia 05/12/1720, o rei D. João V doara aos índios da missão da Ibiapaba "toda a terra que fica em cima da serra, além da que já tinhão se começado da ladeira da Meruoca até o lugar chamado Itapiuna” (AHU - Ceará, Papéis Avulsos, Caixa 6, Doc. 415 , fol. 1). Percebe-se que, ao contrário do que costumava acontecer com as sesmarias na América Portuguesa, não se utilizaram as medidas padronizadas da braça ou da légua, mas apenas a determinação aberta de que se alcançaria toda a terra na parte superior da serra. As justificativas constantes na carta de doação da sesmaria foram os "relevantes serviços, que os taes Indios tem feito a Corôa" (Idem, ibidem), razão à qual se acrescenta o argumento de Lemos de que a presença de tantos índios - estimados em seis mil, segundo trecho subsequente (AHU - Ceará, Papéis Avulsos, Caixa 6, Doc. 415, fol. 2) - favoreceria a defesa da capitania, uma vez que eles seriam "huns soldados, que V. Mag.de. tem muito prontos para tudo, sem com eles gastar nada" (AHU - Ceará, Papéis Avulsos, Caixa 6, Doc. 415, fol. 1).

A seguir, o subscritor passa a relatar os problemas, que seriam principalmente a presença de "pretos brancos" que passaram a ocupar as terras e se "servirem" e "uzarem mal das Indias e Indios" (AHU - Ceará, Papéis Avulsos, Caixa 6, Doc. 415, fol. 1-1v), perturbando a tranquilidade que deveria imperar na missão. Os jesuítas buscaram, sem sucesso, acabar com essas ocupações irregulares, mas os invasores tentaram convencer o capitão-mor de que a área onde eles estavam

16 Sobre o Conselho Ultramarino, cf., entre outros, BICALHO, 2017, p. 137-158; MYRUP, 2015; CAETANO, 1967.

17 Memorial dos ministros. Disponível em: <https://memorialdeministros.weebly.com/ resultado-letrados.html? cbResetParam=1\&IDJuiz=1592> . Acesso em: 05/12/2019. 
não era dos indígenas; a falsa justificativa, segundo Lemos, residia no argumento de que os limites da sesmaria estavam num local chamado Inassu, e não em Itapiúna. De acordo com o ouvidor, que fundamentou a sua posição na língua falada pelos indígenas, isso "he sem dúvida violentar, e adulterar a dita palavra e doaçam, porque a palavra Itapiúna, ou Itabipuna que dizer na lingoa da terra lagoas grandes, e pretas, e estas se não acham no riacho Inassu, so debaixo dagua" (AHU - Ceará, Papéis Avulsos, Caixa 6, Doc. 415, fol. 1v). Ao final, Lemos apresentou o seu pedido ao rei para que declarasse que os índios tinham as referidas sesmarias na área indicada pela doação original, para que que elas fossem utilizadas nas atividades agrícolas (AHU Ceará, Papéis Avulsos, Caixa 6, Doc. 415, fol. 2).

Além da carta-petição, foram anexadas provas para instruir o processo no Conselho Ultramarino. Elas tinham natureza documental e foram praticamente todas produzidas a partir de cópias de documentos feitas por Manuel Jesus Maria, tabelião do Aquiraz em 1756. Tabeliães e notários tiveram uma enorme importância em sociedades dependentes de documentos escritos e cuja organização era baseada na escrita, mas a sua população, paradoxalmente, era majoritariamente analfabeta ${ }^{18}$. Esses agentes tinham fé pública e convertiam em texto escrito o que as partes lhe submetiam verbalmente, desde que isso tivesse uma base normativa; nisso se enquadrava também a elaboração de cópias de documentos originais ou mesmo cópias a partir de outras cópias certificadas.

O primeiro documento foi trasladado pelo tabelião Manuel Jesus Maria $^{19}$ no dia 07/02/1756 a pedido do padre João Brito ${ }^{20}$, do Real Hospício do Aquiraz. Tratava-se de uma carta de sesmaria emitida

18 Para o papel dos notários no mundo jurídico da América Hispânica, cf. HONORES, 2007, p. 200-208. Sobre a relevância da escrita na sociedade colonial brasileira, tema que, para o direito no período, ainda precisa ser mais bem estudado, cf. RACHI, 2016.

19 Para uma lista dos tabeliães da vila de Aquiraz no século XVIII, cf. MACÊDO, 1991, p. $138-146$.

20 Apesar de se falar em "João de Brito" em dois documentos, a referência correta deveria ser a João Brewer, de quem se falará adiante. 
pelo então capitão-mor e governador da capitania do Siará Grande, Gabriel da Silva Lago, em 11/12/1708, a partir de um pedido feito pelo padre Ascenso Gago de que fossem concedidas essas terras "devolutas, e dezaproueitadas" aos índios que viviam nessa serra, com a finalidade de as "povoar para a sua missão em ordem a como dar sustentação dos misionarios, que nella asistem, e ao diante asiterem, para poderem ter carne frescae leyte para o seu pasadio, e algumas criasoins miudas (AHU - Ceará, Papéis Avulsos, Caixa 6, Doc. 415, fol. 3). Na sequência, copia-se a carta de sesmaria em si, concedida pelo governador em nome do rei, pela qual se concedem "todas as agoas, campos, mattos, logradouros, e mais úteis que nelas houverem [sic]" (AHU - Ceará, Papéis Avulsos, Caixa 6, Doc. 415, fol. 3v). Ao final, o tabelião certifica que "não se continha mais nem menos em dita carta e data de sismaria", finalizando o documento com o seu sinal público (AHU - Ceará, Papéis Avulsos, Caixa 6, Doc. 415, fol. 3v-4).

Um segundo traslado foi uma cópia a partir de outra cópia: o que se anexou aos autos foi o traslado da data de sesmaria feito em 06/02/1756 pelo tabelião Manuel Jesus Maria a partir de outra cópia feita pelo à época tabelião público de Aquiraz Crispim Gomes de Oliveira em 09/05/1746. Ou seja, o padre Manuel de Matos, da Companhia de Jesus, apresentou a data de sesmaria para ser traslada e, dez anos depois, o padre João de Brito, também da Companhia, levou essa versão oficial para que fosse novamente copiada e anexada aos autos. O conteúdo do documento original, feito pelo Conselho Ultramarino por ordem do rei D. João V em 10/12/1720, constata que as terras originalmente "demarcadas constavam de muitas penadias, e quebradas, inuteiz e as que erão capazes de plantar, e de darem fruto, além de serem poucas e penadias, estauam ja cansadas, e por esta cauza não tinhão terras capazes aonde podesem plantar" (AHU - Ceará, Papéis Avulsos, Caixa 6, Doc. 415, fol. 5), enfatizando o argumento do cultivo.

Sobre essa petição que motivou a expedição da data de sesmaria em 1720, deve-se esclarecer que ela pode ser encontrada em 
outro documento do Arquivo Histórico Ultramarino, em que o já mencionado argumento da incapacidade das terras aparece expressamente, o que acabava acarretando que muitos indígenas andassem "continuamente fora das aldeas, (...) com auzencias muy prolongadas ordinariamte. de hum anno inteiro" (AHU - Ceará, Papéis Avulsos, Caixa 1, Doc. 65, fol. 1). Em virtude da grande quantidade de pessoas passando pela aldeia, espalhando doenças e "desencabeçam suas filhas, e também as suas mulheres, para fugirem com elles", pediram que o rei ordenasse que "nenhum passageiro tome agasalho em caza particular dos indios, senão na caza dos hospedes, para assim se euitarem innumeraueis escandalos, e offenças de Deus" (AHU - Ceará, Papéis Avulsos, Caixa 1, Doc. 65, fol. 1v). Por fim, argumenta-se que esses índios fiéis à Coroa são vassalos do rei e merecem receber as terras (AHU - Ceará, Papéis Avulsos, Caixa 1, Doc. 65, fol. 1v).

Voltando aos documentos em análise, percebe-se que mais importante do que a compaixão pela precária situação de fome em que se encontravam os indígenas foi o argumento da recompensa, de modo que o documento deixa claras "as justas rezoins deles e se terem feito merecedores pelo serviso que me tem feito na defesa dessas Capitania, e da do Piauhy, na guerra que nelas tem havido com os indios nossos inimigos" (AHU - Ceará, Papéis Avulsos, Caixa 6, Doc. 415, fol. $5 v$ ). Em um contexto de conflito entre grupos indígenas aliados e inimigos dos Portugueses ${ }^{21}$, percebe-se expressamente a diferença de tratamento entre eles, contribuindo decisivamente a presença e até mesmo o ajuntamento com os jesuítas para essa definição. Ser aliado dos portugueses tornava os indígenas súditos e vassalos do rei, sujeitos, assim, a um sistema de recompensas pelos serviços prestados que incluía o recebimento de terras em sesmarias. Neste caso, os indígenas

21 A chamada "guerra dos bárbaros" foi justamente essa sequência duradoura de conflitos entre indígenas aliados e inimigos dos portugueses, principalmente nas capitanias do norte do Estado do Brasil e na fronteira com o Estado do Maranhão. Cf. PUNTONI, 2002; 
da Ibiapaba receberam "toda a terra que fica em sima da serra, alem das que lhes estavam dadas" (AHU - Ceará, Papéis Avulsos, Caixa 6, Doc. 415, fol. 5v).

Para finalizar os documentos relativos a este caso, apresentou-se um despacho de próprio punho do padre João Brewer ${ }^{22}$, visitador-geral do Real Hospício do Ceará, que estava supervisionando as missões da Ibiapaba àquele momento e que apresentou um levantamento da quantidade de indígenas na referida missão. Brewer indicou que havia 6.006 indígenas na data em que assinou o documento, em 13/02/1756 (AHU - Ceará, Papéis Avulsos, Caixa 6, Doc. 416, fol. 1). Na mesma folha, o ouvidor Lemos certificou "serem as letras da certidão acima e sinal ao pé do Rdo. Padre visitador do Hospício do Seará” (Idem, ibidem).

A carta-petição feita pelo ouvidor deu início a um procedimento no Conselho Ultramarino, cuja movimentação interna pode ser visualmente percebida à margem do documento principal, onde foram escritos os despachos encaminhando medidas a serem tomadas no Conselho, bem como assinaturas e rubricas dos conselheiros envolvidos. Esse andamento processual, com a indicação de que outras autoridades indiretamente envolvidas foram comunicadas sobre a questão, se materializa nesses despachos marginais manuscritos.

A decisão do Conselho Ultramarino foi para que se cessassem as invasões das terras dos indígenas da Ibiapaba. O despacho na primeira folha da petição do ouvidor Lemos tem o seguinte teor: "Parece me se deve senhor informar o Governador de Pernambuco recinto por escrito o Cap.am. mor do Siará ao qual deve recomendar que examine que fazer muito esta mostra e exerça os interesses destes por escrito, proibindo que se tome mais terra no sitio sucitado a até a ultima decisão desta materia" (AHU - Ceará, Papéis Avulsos, Caixa 6, Doc. 415, fol. 1). Logo abaixo, na mesma folha, despachou-se, em 18 de setembro de 1756, a deliberação final para remeter cópias ao Governador de Pernambuco

22 Para informações detalhadas do missionário alemão Johannes Josephus Brewer (17181789), inclusive dos seus textos, cf. AYMORÉ, 2005, p. 241-247. 
da decisão tomada. Com isso, o Conselho Ultramarino manteve a posse das terras aos indígenas, assegurando a validade e a continuidade das datas de sesmarias concedidas e confirmadas pelo poder régio. Ao mesmo tempo, foi claro quanto à impossibilidade de invasão das terras demarcadas por quem não vivesse na aldeia, buscando garantir a posse.

$\mathrm{O}$ andamento processual se concluiu com a remessa de cópias da carta ao Governador de Pernambuco, a quem o capitão-mor do Siará Grande estava subordinado à época, em razão da sua condição de capitania subordinada (AHU - Ceará, Papéis Avulsos, Caixa 6, Doc. 415, fol. 1v). O objetivo era fazer com que ele garantisse a eficácia da ordem do Conselho Ultramarino.

\section{CONCLUSÃO}

O caso analisado é exemplar da complexidade do processo de ocupação de vastas áreas do Império Português. Indígenas catequizados e aliados dos portugueses na guerra de conquista dos sertões do norte do Estado do Brasil foram atores que se utilizaram da ordem jurídica portuguesa para terem garantidos os direitos sobre terras que originariamente eram deles. Com o intermédio de jesuítas, os indígenas da Ibiapaba requereram à Coroa a posse da área da serra por meio da concessão de cartas e datas de sesmarias, servindo-se, para isso, do aparato administrativo português e reproduzindo um modelo de peticionamento que buscava ter o direito garantido por meio de decisão do Conselho Ultramarino.

Neste sentido, a ideia de vassalagem é fundamental, pois foi graças a ela que os indígenas puderam requerer a concessão das sesmarias. Aplicou-se diretamente o argumento da retribuição, o que é típico da economia da graça e explicava que a mercê régia (no caso, a doação de sesmarias) dependia de ações do requerente ou dos seus antepassados (aqui, a fidelidade e os serviços prestados). Os índios aliados dos portugueses eram súditos do rei e, tendo auxiliado a 
Coroa na defesa e na guerra contra os seus inimigos, mereciam que lhes fossem concedidas essas terras.

$\mathrm{O}$ argumento do cultivo, pensado no direito português medieval como inerente às sesmarias, foi recorrente e apareceu nos pleitos dos indígenas, na corroboração do ouvidor e nas datas de sesmaria. Concediam-se as terras para o cultivo, as quais deveriam seguir na posse dos sesmeiros enquanto eles as estivessem cultivando. Seguia-se a legislação geral, mas também a específica para a América Portuguesa para que o cultivo fosse condição essencial para a manutenção da posse.

A ação dos principais atores envolvidos nessa contenda (indígenas, jesuítas e oficiais) faz perceber um respeito à ordem jurídica régia, o que envolvia o conhecimento da estrutura normativa para a terra, o reconhecimento da formalidade de procedimentos de peticionamento e da relevância e da centralidade de documentos escritos e dos oficiais responsáveis pelas suas certificações dos escritos e das cópias de documentos. Ou seja, os indígenas sabiam que precisavam pedir ao rei que lhes garantisse o seu direito de posse da terra, os jesuítas sabiam que precisavam guardar os documentos que comprovassem a regularidade jurídica da situação fática de estar na posse de determinada área e o ouvidor e os conselheiros ultramarinos reconheciam que, amparados em toda essa gama de documentos, não haveria outra saída além do deferimento do pedido e da garantia de que essa posse deveria ser preservada. Disso resulta que os notários, por sua vez, tinham uma função central nessas questões, porque detinham, em razão da sua fé pública, o poder de criar documentos (neste caso, traslados de outros que lhes foram apresentados) com decisivo valor probatório.

Tudo o que se afirmou pode ser consubstanciado no debate sobre o papel do justo título quando se discutiram poderes sobre terras no Império Português moderno. Longe de se afirmar que questões fáticas não foram relevantes, o que se pretende aqui é ressaltar que a formalização da situação jurídica dependia do seu reconhecimento pela Coroa, cuja materialização eram justamente a carta e a data de sesmaria, documentos escritos oponíveis a qualquer pessoa. Ocupar terras atribuídas a alguém 
por meio de uma data de sesmaria era uma situação que a Coroa poderia reprimir, como neste caso. Ao fazê-lo, ela proclamava que a situação jurídica, materializada no justo título da sesmaria, deveria prevalecer sobre as imposições fáticas relativas à ocupação dessas áreas por quem não tinha o título a elas relativo. E tudo isso em uma região periférica da Capitania do Siará Grande, que, por sua vez, também era uma zona periférica na América Portuguesa, o que não impediu a difusão desse modelo para o tratamento jurídico da terra.

Isso não significa, em absoluto, que essa presença da Coroa na regularização de conflitos relativos à terra tenha sido uma constante no período colonial. É difícil comprovar empiricamente a efetividade dessas medidas, inclusive para o próprio caso em análise, cujos desdobramentos não são o foco deste texto (XAVIER, 2010, p. 52-80). Suspeita-se, porém, que, diante das dificuldades e da precariedade da estrutura administrativa da Coroa, as situações de fato devam ter sido mais frequentes. O que o caso dos indígenas da Ibiapaba revela, porém, é uma tendência, em meados do século XVIII, de se seguir a determinação da Coroa sobre o tema, a qual, para esta e tantas outras situações, se materializava por meio do título da sesmaria. Portanto, esse título era menos importante pela sua existência em si enquanto documento escrito (até porque cópias oficiais poderiam ser feitas pelos tabeliães públicos e tinham o mesmo poder intrínseco) e mais por ele significar uma decisão tomada pela autoridade régia sobre como deveria ser usado aquele pedaço de terra.

\section{REFERÊNCIAS}

\section{Fontes Primárias Manuscritas}

AHU - Ceará, Papéis Avulsos, Caixa 1, Doc. 65.

AHU - Ceará, Papéis Avulsos, Caixa 6, Doc. 415.

AHU - Ceará, Papéis Avulsos, Caixa 6, Doc. 416. 


\section{Literatura}

AGUIAR, Cláudio. Padre Antônio Vieira e a missão jesuítica da Serra de Ibiapaba (1655-1759). Revista do Instituto Histórico e Geográfico Brasileiro, n. 172, v. 452, 2011, p. 507-546.

ALVEAL, Carmen Margarida Oliveira; BARBOSA, Kleyson Bruno Chaves. A legitimidade da graça: os impactos da tentativa de reforço da política sesmarial sobre as terras da Casa da Torre na capitania da Paraíba (século XVIII). In: Topoi, Rio de Janeiro, v. 16, n. 30, 2015, p. 78-100.

ALVEAL, Carmen Margarida Oliveira; BARBOSA, Kleyson Bruno Chaves. De senhorio colonial a território de mando: os acossamentos de Antônio Vieira de Melo no Sertão do Ararobá (Pernambuco, século XVIII). Revista Brasileira de História, 2016, v. 35, n. 70, p. 41-64.

ALVEAL, Carmen Margarida Oliveira; BARBOSA, Kleyson Bruno Chaves. Transformações na legislação sesmarial, processos de demarcação e manutenção de privilégios nas terras das capitanias do norte do estado do Brasil. Estudos Históricos, v. 28, n. 56, 2015, p. 247-263.

AYMORÉ, Fernando Amado. Jesuiten aus Zentraleuropa in Portugiesisch- und Spanisch-Amerika: ein bio-bibliographisches Handbuch mit Überblick über das außereuropäische Wirken der Gesellschaft Jesu in der frühen Neuzeit. Band 1: Brasilien (1618-1760). Münster: Aschendorff Verlag, 2005.

BANDEIRA, Moniz. O feudo: a Casa da Torre de Garcia d'Ávila: da conquista dos sertões à Independência do Brasil. Rio de Janeiro: Civilização Brasileira, 2000.

BICALHO, Maria Fernanda; COSTA, André. O Conselho Ultramarino e a emergência do secretário de Estado na comunicação política entre reino e conquistas. In: FRAGOSO, João; MONTEIRO, Nuno Gonçalo (Org.). Um reino e suas repúblicas no Atlântico: comunicações políticas entre Portugal, Brasil e Angola nos séculos XVII e XVIII. Rio de Janeiro: Civilização Brasileira, 2017, p. 137-158.

CABRAL, Gustavo César Machado. Ius commune: uma introdução à história do direito comum do Medievo à Idade Moderna. Rio de Janeiro: Lumen Juris, 2019.

CABRAL, Gustavo César Machado. Jesuitic pragmatic literature and ecclesiastical normativity in Portuguese America (16th-18th centuries). In: DUVE, Thomas; DANWERTH, Otto (Org.). Knowledge of the 
pragmatici: Legal and Moral Theological Literature and the Formation of Early Modern Ibero-America (Max Planck Studies in Global Legal History of the Iberian Worlds, 1). Leiden/Boston: Brill, 2020, p. 151-186.

CABRAL, Gustavo César Machado. Literatura jurídica e prática processual no Portugal Seiscentista: o uso de casos julgados nas 'Resolutiones forenses practicabiles' de Manuel Álvares Pegas. Cadernos do Programa de Pós-Graduação em Direito - PPGDIR/UFRGS, v. 14, 2019, p. 301-326. CABRAL, Gustavo César Machado. Os jesuítas e a construção da ordem jurídica: uma contribuição ao estudo da normatividade dos catecismos e confessionários na América Portuguesa (séculos XVII-XVIII). Nomos: Revista do Programa de Pós-Graduação em Direito - UFC, Fortaleza, v. 39.2, jul./dez. 2019, p. 275-297. <http://periodicos.ufc.br/nomos/ issue/view/859/299>. Acesso em: 09/01/2020.

CABRAL, Gustavo César Machado. Os senhorios na América Portuguesa: o sistema de capitanias hereditárias e a prática da jurisdição senhorial (séculos XVI a XVIII). Jahrbuch für Geschichte Lateinamerikas, v. 52, 2015, p. 65-86.

CAETANO, Marcello. O Conselho Ultramarino: esboço de sua história. Lisboa: Agência Cultural do Ultramar, 1967.

CARVALHO, Reinaldo Forte. Agentes da Justiça e os representantes do poder local no Ceará setecentista. In: BICALHO, Maria Fernanda; ASSIS, Virgínia Maria Almoêdo de; MELLO, Isabele de Matos Pereira de (Org.). Justiça no Brasil colonial: agentes e práticas. São Paulo: Alameda, 2017, p. 189-208.

CASTAÑEDA DELGADO, Paulino. La condición miserable del indio y sus privilegios. Anuario de Estudios Americanos, v. 28, 1971, p. 245-335.

CHORÃO, Maria José Mexia Bigotte (Org.). Doações e forais das capitanias do Brasil, 1534-1536. Lisboa: Instituto dos Arquivos Nacionais/ Torre do Tombo, 1999.

CLAVERO, Bartolomé. Sujeto de derecho entre estado, género y cultura. Santiago: Olejnik, 2016.

COSTA, Mário Júlio de Almeida. Origem da enfiteuse no direito português. Coimbra: Coimbra, 1957.

CUNILL, Caroline. El indio miserable: nacimiento de la teoria legal em la América colonial del siglo XVI. Cuadernos Inter.c.a.mbio, v. 8, n. 9, 2011, p. 229-248. 
DELSON, Roberta Marx. Novas Vilas Para o Brasil-Colônia: planejamento Espacial e Social no Século XVIII. Brasília - ALVA-CIORD, 1997.

DUVE, Thomas. Algumas observações sobre o modus operandi e a prudência do juiz no Direito canônico indiano. Revista da Faculdade de Direito da UFRGS, n. 37, 2017, p. 52-79.

DUVE, Thomas. Sonderrecht in der Frühen Neuzeit: Studien zum ius singulare und den privilegia miserabilium personarum, senun und indorum in Alter und Neuer Welt. Frankfurt am Main, 2008.

FILIPPINI, Giovanni Crisostomo. De privilegiis ignorantiae tractatus moralis. Venetiis: Petri Antonii Brigoncii, 1686.

FRANCO, Renato; PATUZZI, Silvia. Governar a miséria: escravidão, pobreza e cidade na América Portuguesa no início do século XVIII. Revista de História, n. 178, 2019, p. 2-27.

GARCIA, Elisa Frühauf. Las categorias de la conquista: las mujeres nativas en el vocabulário del siglo XVI (São Vicente, Brasil). Nuevos Mundo Mundos Nuevos, 2019. Disponível em: <http://journals.openedition. org/nuevomundo/75613>. Acesso em: 05/12/2019.

HERZOG, Tamar. Colonial law and "native customs": indigenous land rights in Colonial Spanish America. The Americas, v. 69, n. 3, 2013, p. 303-321. HESPANHA, António Manuel. As fronteiras do poder. O mundo dos rústicos. A ordem do mundo e o saber do jurista: imaginários do antigo direito europeu. Lisboa: CreativeSpace Independent Publishing, 2017, p. 199-278.

HESPANHA, António Manuel. As outras razões da política: a economia da "graça". A ordem do mundo e o saber do jurista: imaginários do antigo direito europeu. Lisboa: CreativeSpace Independent Publishing, 2017, p. 121-162.

HESPANHA, António Manuel. As vésperas do Leviathan: instituições e poder político: Portugal - século XVII. Coimbra: Almedina, 1994.

HESPANHA, António Manuel. Como os juristas viam o mundo: direitos, estados, pessoas, coisas, contratos, ações e crimes. Lisboa: CreativeSpace Independent Publishing, 2015, p. 345-348.

HONORES, Renzo. Una sociedade legalista: abogados, procuradores de causas y la creación de una cultura legal colonial en Lima y Potosí, 15401670. Tese (Doutorado em História), Florida International University, 2007. 
JUCÁ NETO, Clovis Ramiro. Os primórdios da organização do espaço territorial e da vila cearense - algumas notas. Anais do Museu Paulista, n. 20, v. 1, 2012, p. 133-163.

LEITE, Serafim. História da Companhia de Jesus no Brasil. Tomo 3: Norte - 1) fundações e entradas, séculos XVII-XVIII. Rio de Janeiro: Instituto Nacional do Livro, 1943.

MACÊDO, Deoclécio Leite de. Notariado cearense: história dos cartórios do Ceará. Volume 1: Abaiara a Aurora. Fortaleza: Expressão Gráfica, 1991. MAIA, Lígio José de Oliveira. Serras de Ibiapaba. De aldeia à vila de Índios: Vassalagem e Identidade no Ceará colonial - Século XVIII. Tese (Doutorado em História) - Instituto de Ciências Humanas e Filosofia, Universidade Federal Fluminense. Rio de Janeiro, 2010, p. 20.

MCKINLEY, Michelle A. Fractional freedoms: slavery, intimacy, and legal mobilization in Colonial Lima, 1600-1700. New York: Cambridge University Press, 2016.

MENEZES, Jeannie da Silva. Escrivães da ouvidoria e Tabeliães do judicial de Pernambuco. Notas de pesquisa sobre o "encarte" nesses ofícios no século XVIII. In: BICALHO, Maria Fernanda; ASSIS, Virgínia Maria Almoêdo de; MELLO, Isabele de Matos Pereira de (Org.). Justiça no Brasil colonial: agentes e práticas. São Paulo: Alameda, 2017, p. 161-187.

MOHNHAUPT, Heinz. Erteilung und Widerruf von Privilegien nach der gemeinrechtlichen Lehre vom 16. bis 19. Jahrhundert. In: MOHNHAUPT, Heinz. Historische Vergleichung im Bereich von Staat und Recht. Frankfurt am Main: Vittorio Klostermann, 2000, p. 371-399.

MOHNHAUPT, Heinz. Privileg. In: CORDES, Albrecht et all (Org.). Handwörterbuch zur deutschen Rechtsgeschichte. v. 28. 2ed. Aachen: Erich Schmidt Verlag, 2018, p. 821-828.

MOHNHAUPT, Heinz. Privatrecht in Privilegien. In: MOHNHAUPT, Heinz. Historische Vergleichung im Bereich von Staat und Recht. Frankfurt am Main: Vittorio Klostermann, 2000, p. 275-294.

MOLINA, Ludovico de. De hispanorum primogeniorum origine ac natura libri quatuor. Coloniae: Ioannis Baptistae Ciotti Senensis, 1588. MYRUP, Erik Lars. Power and corruption in the Early Modern Portuguese World: connections across the Portuguese Seaborne Empire. Baton Rouge: Louisiana State University Press, 2015. 
NOGUEIRA, Gabriel Parente. Viver à lei da nobreza: elites locais e o processo de nobilitação na capitania do Siará Grande (1748-1804). Curitiba: Appris, 2017.

NORONHA, Ibsen. Aspectos do direito no Brasil quinhentista: consonâncias do espiritual e do temporal. Coimbra: Almedina, 2008.

OLIVEIRA, Almir Leal. As carnes secas do Ceará e o mercado atlântico no século XVIII. In: DORÉ, Andréa; SANTOS, Antônio Cesar de Almeida (Org.). Temas setecentistas: governos e populações no Império Português. Curitiba: UFPR/SCHLA- Fundação Araucária, 2009, p. 505-516.

PEREIRA, Francisco Caldas. Commentarivs analyticvs, de renovatione emphyteutica. Ulyssippone, Emmanuel de Lyra Typo., 1585.

PORTUGAL, Domingos Antunes. Tractatus de donationibus jurium et bonorum regiae coronae. 2 t. Lugduni: Anisson, \& Posuel, 1699.

PUNTONI, Pedro. A guerra dos bárbaros. São Paul: Fapesp/Hucitec/Edusp, 2002.

RACHI, Silvia. Por mãos alheias: usos da escrita na sociedade colonial. Belo Horizonte: Editora PUC Minas, 2016.

SOTO, Domingo de. De iustitia et iure. Lugduni: Bartholomaeum Honoratvm, 1582.

VARELA, Laura Beck. Das sesmarias à propriedade moderna: um estudo de história do Direito Brasileiro. Rio de Janeiro: Renovar, 2005.

XAVIER, Maico Oliveira. "Cabôcullos são os brancos”: dinâmicas das relações sócio-culturais dos índios do Termo da Vila Viçosa Real - século XIX. Dissertação (Mestrado em História Social). Programa de Pós-Graduação em História Social, Universidade Federal do Ceará, 2010.

\section{GUSTAVO CÉSAR MACHADO CABRAL}

Professor Adjunto da Faculdade de Direito da Universidade Federal do Ceará (UFC). Coordenador do Programa de Pós-Graduação em Direito da UFC. Bolsista de Produtividade do CNPQ (PQ2). Doutor em História do Direito pela Universidade de São Paulo 
(USP). Pós-Doutorado pelo Max-Planck Institut für europäische Rechtsgeschichte (Frankfurt am Main/Alemanha). Foi professor visitante nas Universidades Autônoma de Madrid (Espanha), Maastricht (Holanda) e Nova de Lisboa (Portugal) e pesquisador visitante na Brown University (2021-2022). Foi pesquisador associado ao Max-Planck Institut für europäische Rechtsgeschichte (Frankfurt am Main/Alemanha).

Endereço profissional: Faculdade de Direito da Universidade Federal do Ceará, R. Meton de Alencar, s/n, Centro, Fortaleza - CE, 60035-160, Brasil.

ORCID ID: https://orcid.org/0000-0001-8565-1328

E-MAIL: gustavocesarcabral@gmail.com

\section{ANA CAROLINA FARIAS ALMEIDA DA COSTA}

Doutoranda em Direito pela Universidade Federal do Ceará. Mestre em Direito Constitucional pela Universidade de Fortaleza e Mestre em Políticas Públicas pela Universidade Estadual do Ceará. Tabelião e registradora.

Endereço profissional: Faculdade de Direito da Universidade Federal do Ceará, R. Meton de Alencar, s/n, Centro, Fortaleza - CE, 60035-160, Brasil.

ORCID ID: https://orcid.org/0000-0002-3365-9958

E-MAIL: carolinafarias.ac@gmail.com

Recebido: $12 / 06 / 2020$

Aceito: $28 / 10 / 2020$ 